\title{
ANALISIS POSTUR KERJA MENGGUNAKAN METODE RAPID UPPER LIMB ASSESSMENT (RULA) STUDI KASUS PT. TJ FORGE INDONESIA
}

\author{
Nurul Dzikrillah dan Euis Nina Saparina Yuliani \\ Program Studi Magister Teknik Industri,Universitas Mercubuana \\ e-mail: nuruldzikrillah@gmail.com; ensy08@yahoo.com
}

\begin{abstract}
ABSTRAK
Desain tempat kerja akan sangat bergantung pada jenis pekerjaan dan alat atau fasilitas yang digunakan untuk menunjang pelaksanaan operasi kerja. Salah satu departemen dalam PT. TJ Forge Indonesia adalah departemen Forging, Seksi Heat Treatment. Pada departemen ini terdapat aktivitas pengecekan kekerasan (hardness) part. Jika dilihat dari desain tempat kerja, maka salah satu faktor yang dapat menentukan ketidak nyamanan pekerja adalah kurangnya alat bantu mekanis yang digunakan. Opertor (pekerja) sering merasakan kelelahan pada bagian punggung dan leher. Analisis ergonomi akan dilakukan untuk menentukan alat bantu mekanis. Dalam penelitian ini, metode yang digunakan untuk menganalisis sikap dan posisi kerja menggunakan metode Rapid Upper Limb Assessment (RULA). Metode RULA digunakan untuk mengestimasi terjadinya risiko gangguan otot skeletal. Hasil yang diperoleh dari penelitian ini adalah sikap kerja operator yang melakukan pengecekan hardness dengan posisi membungkuk setelah diinvestigasi dengan menggunakan RULA checksheet mendapatkan hasil final score +5 yang berarti investigate further and change soon (perlu diinvestigasi lebih lanjut dan segera lakukan perubahan). Rekomendasi yang diberikan adalah dengan menambahkan alat bantu (support) dengan menambah ketinggian meja kerja agar operator tidak lagi membungkuk. Sikap dan posisi kerja operator dihitung lagi dengan mengunakan RULA checksheet dan hasilnya adalah +2 (acceptable) atau dapat diterima.
\end{abstract}

Kata Kunci: Ergonomi, Postur Kerja, RULA,

\begin{abstract}
Workplace design is depend on some type of the job and facility that used for supporting the job itself. Heat Treatment Section is part of forging department in PT TJ Forge Indonesia. This department functioned as checking for hardness part. In this area, one thing that determine about comfortable in workplace is about facility. Operators feel uncomfortable while working in their body, such as back and neck. Ergonomics analysis has been done to reveal this problem. In this research, Rapid Upper Limb Assessment (RULA) has been used to analyze work position. The result shows that final score is +5 which mean needs investigate further and change soon. Recommendation has been proposed to give some additional part in order to prevent operators in bent position. After this proposed, work position was measured by RULA and the result is +2 which mean is acceptable.
\end{abstract}

Keywords: Ergonomics, Posture Work, RULA,

\section{PENDAHULUAN}

Desain tempat kerja akan sangat bergantung pada jenis pekerjaan dan alat atau fasilitas yang digunakan untuk menunjang pelaksanaan operasi kerja. Salah satu upaya dilakukan untuk menghasilkan produk yang berkualitas diantaranya memperhatikan bahaya dan risiko diantaranya lingkungan, kesehatan dan keselamatan kerja. Penerapan ergonomi perlu mendapatkan perhatian yang cukup karena kurangnya perhatian terhadap penerapan ergonomi di tempat kerja sehingga risiko bahaya yang ada dapat dikurangi.

PT. TJ Forge Indonesia adalah perusahaan manufaktur, berlokasi di daerah Karawang, Jawa Barat, yang bergerak di bidang otomotif dengan spesialisasi produk berupa pitman arm, tie rod arm, knuckle, beam, dan produk hasil casting lainnya yaitu diff box dan diff carrier. Di perusahaan ini terdapat berbagai aktivitas seperti berjalan, duduk, berdiri, mendorong, mengangkat, menarik dan lain sebagainya. Semua aktivitas tersebut berhubungan langsung dengan berbagai alat, sistem kerja dan produk yang berada di lingkungan kerja sekaligus menunjang akan kesehatan dan keselamatan dalam diri manusia. Meskipun perkembangan teknologi sudah mulai berkembang namun tidak menutup kemungkinan tidak semua aktivitas dapat dilakukan dengan mesin secara otomatis, terkadang ada pekerjaan yang masih 
menggunakan tenaga manusia. Oleh karena itu, peranan ilmu tentang ergonomi sangatlah penting dalam merancang sebuah sistem kerja yang baik dan benar agar tercipta suasana kerja yang aman, nyaman dan sehat bagi karyawan.

Keluhan musculoskeletal adalah keluhan pada bagian-bagian otot skeletal yang dirasakan oleh seseorang mulai dari keluhan yang sangat ringan sampai sangat sakit [1]. Apabila otot menerima beban statis secara berulang dalam jangka waktu yang lama akan dapat menyebabkan keluhan berupa kerusakan pada sendi, ligamen dan tendon. Keluhan inilah yang biasanya disebut sebagai musculoskeletal disorder (MSDs) atau cedera pada sistem musculoskeletal.

Hasil pengamatan yang telah dilakukan sebelumnya dari departemen Forging, Seksi Heat Treatment ditemukan bahwa ada beberapa pekerjaan yang dapat menimbulkan cedera. Operator merasakan rasa sakit atau cepat lelah karena prosedur kerja dan perancangan fasilitas kerja yang kurang ergonomis, kondisi ini akan memberikan dampak pada hasil produktivitas kerja yang tidak optimal selain berpotensi cedera pada bagian tubuh tertentu akibat aktivitas kerja yang tidak seimbangan dengan keterbatasan manusia [2].

Kondisi tersebut di atas bila dibiarkan secara terus-menerus dapat menimbulkan potensi cedera atau nyeri punggung (low back pain) terhadap operator dan dalam jangka waktu yang panjang. Untuk mengurangi potensi cedera dan bahaya yang terjadi harus segera dilakukan perbaikan.

Analisis postur kerja pada PT. TJ Forge Indonesia akan menggunakan metode RULA (Rapid Upper Limb Assessment).

\section{Ergonomi}

\section{TINJAUAN PUSTAKA}

Istilah "ergonomi" berasal dari bahasa latin yaitu ERGON (KERJA) dan NOMOS (HUKUM ALAM) dan dapat didefinisikan sebagai studi tentang aspek-aspek manusia dalam lingkungan yang ditinjau secara anatomi, fisiologi, psikologi, engineering, manajemen dan desain atau perancangan [3]. Ergonomi adalah suatu cabang ilmu yang sistematis untuk memanfaatkan informasi-informasi mengenai sifat, kemampuan dan keterbatasan manusia untuk merancang suatu sistem kerja sehingga orang dapat hidup dan bekerja pada sistem itu dengan baik, yaitu mencapai tujuan yang diinginkan melalui pekerjaan itu dengan efektif, aman, sehat dan nyaman [1].

Postur kerja merupakan titik penentu dalam menganalisis keefektivan dari suatu pekerjaan. Apabila postur kerja yang dilakukan oleh operator sudah baik dan ergonomis maka dapat dipastikan hasil yang diperoleh oleh operator tersebut akan baik, akan tetapi bila postur kerja operator tersebut salah atau tidak ergonomis maka operator tersebut mudah kelelahan dan terjadi kelainan pada bentuk tulang. Apabila operator mudah mengalami kelelahan hasil pekerjaan yang dilakukan operator tersebut juga mengalami penurunan dan tidak sesuai denganyang diharapkan [4].

Keluhan otot skeletal pada umumnya terjadi karena kontraksi otot yang berlebihan akibat pemberian beban kerja yang terlalu berat dengan durasi pembebanan yang panjang. Sebaliknya, keluhan otot kemungkinan tidak terjadi apabila kontraksi otot hanya berkisar antara15-20\% dari kekuatan otot maksimum. Namun apabila kontraksi otot melebihi 20\%, maka peredaran darah ke otot berkurang menurut tingkat kontraksi yang dipengaruhi oleh besarnya tenaga yang diperlukan. Supply oksigen ke otot menurun, proses metabolisme karbohidrat terhambat dan sebagai akibatnya terjadi penimbunan asam laktat yang menyebabkan timbulnya rasa nyeri otot. [4].

Terdapat beberapa faktor yang dapat menyebabkan terjadinya keluhan otot skeletal, diantaranya yaitu:

1. Peregangan otot yang berlebihan (over exertion), pada umumnya sering dikeluhkan oleh pekerja dimana aktivitas kerjanya menuntut pengerahan tenaga yang besar seperti aktivitas mengangkat, mendorong, menarik dan menahan beban yang berat. Peregangan otot yang berlebihan ini terjadi karena pengerahan tenaga yang diperlukan melampaui otot. Apabila hal serupa sering dilakukan dapat mempertinggi risiko terjadinya keluhan otot, bahkan dapat menyebabkan terjadinya cedera otot skeletal. 
2. Aktivitas berulang, yaitu pekerjaan yang dilakukan secara terus menerus seperti pekerjaan mencangkul, membelah kayu besar, angkat-angkut dan sebagainya. Keluhan otot terjadi karena otot menerima tekanan akibat beban kerja secara terus menerus tanpa memperoleh kesempatan untuk relaksasi.

3. Sikap kerja tidak alamiah, yaitu sikap kerja yang menyebabkan posisi bagian-bagian tubuh bergerak menjauhi posisi alamiah, misalnya pergerakan tangan terangkat, punggung terlalu membungkuk, kepala terangkat, dan sebagainya. Semakin jauh posisi bagian tubuh dari pusat gravitasi tubuh, semakin tinggi pula risiko terjadinya keluhan otot skeletal. Sikap kerja tidak alamiah ini pada umumnya karena karakteristik tuntutan tugas, alat kerja dan stasiun kerja tidak sesuai dengan kemampuan dan keterbatasan pekerja.

4. Faktor penyebab sekunder, yaitu: tekanan, getaran dan mikroklimat.

5. Penyebab kombinasi, yaitu: umur, jenis kelamin, kebiasaan merokok, kesegaran jasmani, kekuatan fisik, ukuran tubuh (anthropometri).

Berdasarkan rekomendasi dari Occupational Safety and Health Administration (OSHA), tindakan ergonomik untuk mencegah adanya sumber penyakit adalah melalui dua cara, yaitu:

1. Rekayasa Teknik

a. Eliminasi, yaitu dengan menghilangkan sumber bahaya yang ada.

b. Substitusi, yaitu mengganti alat lama dengan alat baru yang aman, menyempurnakan proses produksi dan menyempurnakan prosedur penggunaan peralatan.

c. Partisi, yaitu melakukan pemisahan antara sumber bahaya dengan pekerja.

d. Ventilasi, yaitu dengan menambah ventilasi untuk mengurangi risiko sakit.

2. Rekayasa manajemen yang berupa pendidikan dan pelatihan, pengaturan waktu kerja dan istirahat yang seimbang, pengawasan yang intensif [2].

\section{RULA}

RULA dikembangkan oleh Dr. Lynn Mc Attamney dan Dr. Nigel Corlett yang merupakan ergonom dari universitas di Nottingham (University's Nottingham Institute of Occupational Ergonomics). Pertama kali dijelaskan dalam bentuk jurnal aplikasi ergonomic pada tahun 1993 [1]. RULA diperuntukkan dan dipakai pada bidang ergonomi dengan bidang cakupan yang luas [5].

Teknologi ergonomi mengevaluasi postur atau sikap, kekuatan dan aktivitas otot yang menimbulkan cedera akibat aktivitas berulang (repetitive strain injuries). Ergonomi diterapkan untuk mengevaluasi hasil pendekatan yang berupa skor risiko antara satu sampai tujuh, skor tertinggi menandakan level yang mengakibatkan risiko yang besar atau berbahaya untuk dilakukan dalam bekerja. Hal ini bukan berarti bahwa skor terendah akan menjamin pekerjaan yang diteliti bebas dari ergonomic hazard. Oleh sebab itu metode RULA dikembangkan untuk mendeteksi postur kerja yang berisiko dan dilakukan perbaikan sesegera mungkin [6].

Metode ini menggunakan diagram body postures dan empat tabel penilaian yang disediakan untuk mengevaluasi postur kerja yang berbahaya dalam siklus pekerjaan tersebut. Melalui metode ini akan didapatkan nilai batasan maksimum dan berbagai postur pekerja, nilai batasan tersebut berkisar antara nilai $1-7$ [8].

\section{METODE PENELITIAN}

Penelitian dilakukan di PT. TJ Forge Indonesia, Karawang, Jawa Barat dan data diperoleh dari hasil wawancara langsung degan operator observasi di tempat kerja dengan mengamati langsung pada proses heat treatment. Pengolahan data dilakukan dengan menggunakan metode RULA.

\section{HASIL DAN PEMBAHASAN}

Berdasarkan hasil dari wawancara kepada operator seksi heat treatment PT TJ Forge Indonesia, selama melakukan pekerjaan pengecekan hardness, operator merasakan mudah lelah di bagian leher dan punggung. Kelelahan ini dirasakan karena adanya beban 
Tabel 1. Rekap Perhitungan Skor RULA (Sebelum Perbaikan)

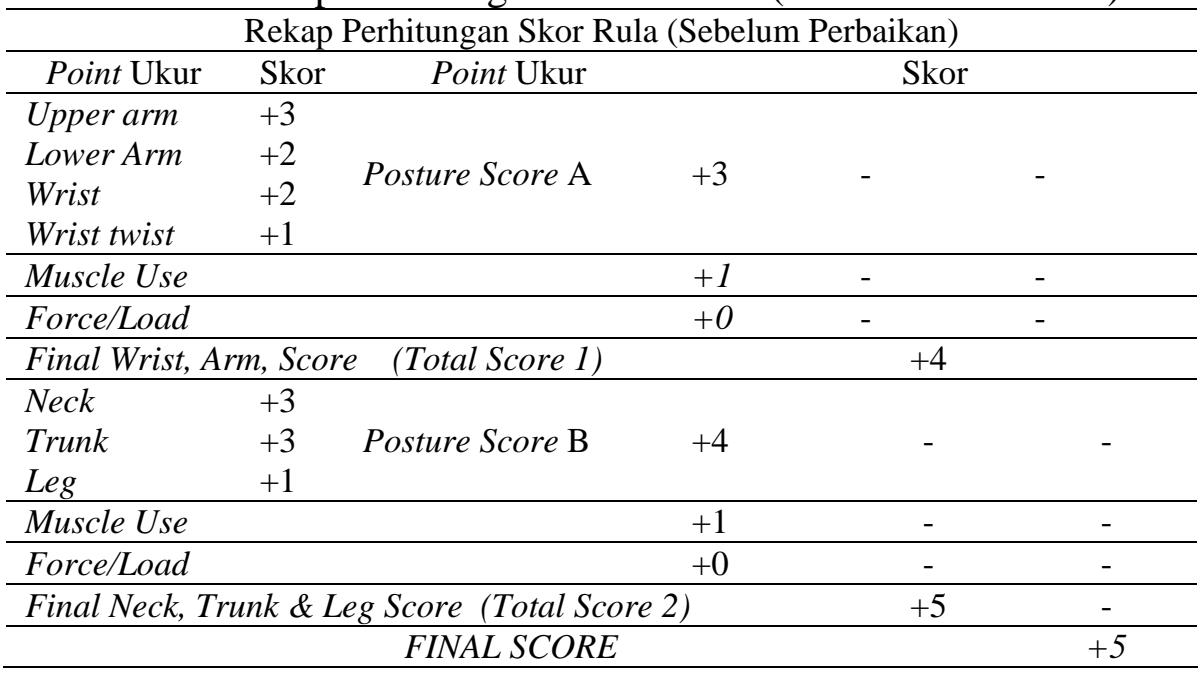

kerja berlebih pada bagian leher dan punggung karena operator menunduk dengan repetitive (dilakukan berulang-ulang).

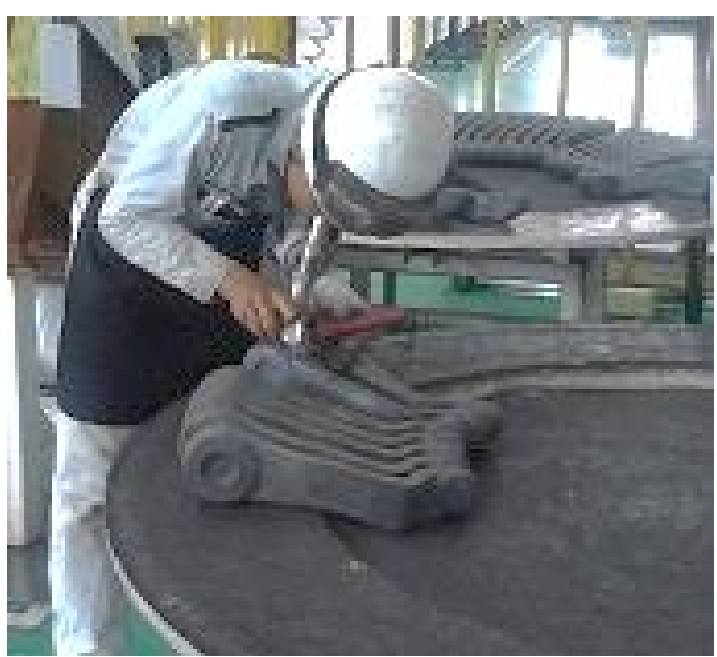

Gambar 1. Posisi Kerja Operator Sebelum Perbaikan

Kemudian menindaklanjuti keluhan operator, maka dilakukan investigasi terhadap postur kerja. Investigasi postur kerja dilakukan menggunakan RULA check sheet dan didapat hasil seperti pada Tabel 1.

Hasil yang didapat adalah level 5, yang berarti masuk kategori Investigate further and change soon (Perlu diinvestigasi lebih lanjut dan segera dilakukan perubahan). Dari rekap perhitungan RULA dapat dilihat bahwa point yang memberikan kontribusi nilai RULA menjadi tinggi adalah pada bagian Neck, Trunk $\&$ Leg Score dengan nilai +5 , maka bagian ini perlu dilakukan perbaikan. Tingginya nilai tersebut dikarenakan postur kerja operator membungkuk, sehingga bagian leher dan punggung memiliki beban yang besar.

Usulan yang diberikan adalah memberikan alat bantu (support) dengan cara meninggikan stasiun kerja agar operator tidak membungkuk serta diharapkan dapat meminimalisir beban kerja di sekitar leher dan punggung, sehingga operator tidak cepat mengalami kelelahan. Rekomendasi perbaikan yang diakukan adalah dengan menambahkan tinggi meja kerja. Penambahan ketinggian meja kerja menggunakan alat bantu (support) yang dibuat dari material besi yang bias menopang beban meja kerja dengan ketinggian $\pm 30 \mathrm{~cm}$. Penambahan ketinggian ini dimaksudkan agar operator tidak lagi menunduk dalam melakukan pengecekan hardness.

Penambahan ukuran $+30 \mathrm{~cm}$ berdasarkan atas perhitungan pengukuran tinggi badan pengguna (operator). Jumlah populasi pengguna untuk meja kerja ini adalah 6 orang dengan sistem penggunaan per shift 1 orang dan digunakan bergantian. Data tinggi operator diperlihatkan pada Tabel 2.

Berdasarkan data tinggi badan pengguna di atas data terlihat bahwa tinggi badan operator hampir seragam. Rataan untuk tinggi badan pengguna adalah $167 \mathrm{~cm}$. untuk melakukan perancangan meja kerja diperlukan data anthropometri tinggi siku berdiri, untuk melihat diperlukan penambahan tinggi seberapa banyak pada meja kerja. Data tinggi meja kerja adalah 
$79 \mathrm{~cm}$ Data anthropometri tinggi siku seperti pada Tabel 3.

Tabel 2. Tinggi Badan Pengguna

\begin{tabular}{lll}
\hline No & Pengguna & Tinggi Badan $(\mathrm{cm})$ \\
\hline 1 & Operator 1 & 168 \\
2 & Operator 2 & 167 \\
3 & Operator 3 & 167 \\
4 & Operator 4 & 166 \\
5 & Operator 5 & 168 \\
6 & Operator 6 & 167 \\
\hline
\end{tabular}

Tabel 3. Tinggi Siku Berdiri Pengguna

\begin{tabular}{lll}
\hline No & Pengguna & Tinggi Siku Berdiri $(\mathrm{cm})$ \\
\hline 1 & Operator 1 & 105 \\
2 & Operator 2 & 105 \\
3 & Operator 3 & 107 \\
4 & Operator 4 & 106 \\
5 & Operator 5 & 105 \\
6 & Operator 6 & 107 \\
\hline
\end{tabular}

Berdasarkan data di atas dapat dilihat rentang data berada pada nilai 105-107 cm. Dengan nilai rataan $106 \mathrm{~cm}$, toleransi yang dipakai adalah tinggi sol sepatu $3 \mathrm{~cm}$. Maka total tinggi siku pengguna adalah $109 \mathrm{~cm}$. Maka, meja kerja harus ditinggikan menjadi $109 \mathrm{~cm}$. Penambahan tinggi meja kerja dibantu dengan menambahkan alat bantu (support) setinggi $30 \mathrm{~cm}$ dengan terlihat pada Gambar 2 .

Setelah dilakukan penambahan ketinggian meja kerja, maka diinvestigasi lagi postur kerja operator pada saat melakukan pengecekan tanpa membungkuk. Investigasi postur kerja masih menggunakan RULA check sheet dan didapat hasil seperti pada Tabel 4.

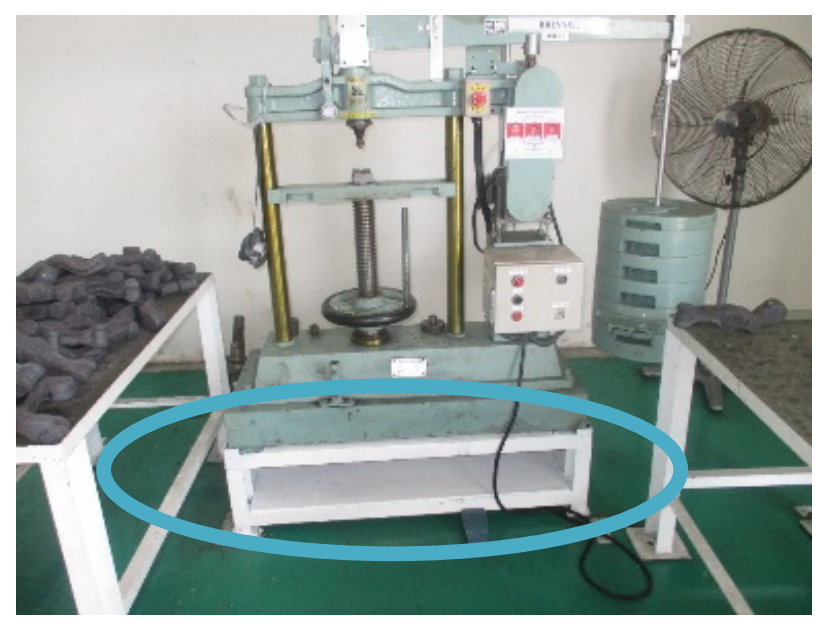

Gambar 2. Penambahan Tinggi Meja Kerja

Pada Gambar 3 terlihat operator sudah tidak membungkuk lagi setelah stasiun kerja ditinggikan dengan alat bantu. Penambahan ketinggian ini diharapkan agar operator tidak mengalami kelelahan karena beban kerja berlebih pada bagian leher dan punggung.

Dari hasil perhitungan RULA setelah perbaikan terjadi pengurangan level skor RULA yang sebelumnya 5, setelah perbaikan dan dilakukan perhitungan ulang menjadi 2, yang berarti masuk kategori acceptable (dapat diterima). Pengurangan skor ini terjadi karena pada poin neck, trunk dan leg tidak lagi tinggi, yaitu 2 (skor sebelumnya 4).

Tabel 4. Rekap Perhitungan Skor RULA (Setelah Perbaikan)

\begin{tabular}{|c|c|c|c|c|c|}
\hline \multicolumn{6}{|c|}{ Rekap Perhitungan Skor Rula (Sebelum Perbaikan) } \\
\hline Point Ukur & Skor & Point Ukur & & Skor & \\
\hline Upper Arm & +1 & \multirow{4}{*}{ Posture Score A } & \multirow{4}{*}{+1} & \multirow{4}{*}{ - } & \multirow{4}{*}{-} \\
\hline Lower Arm & +1 & & & & \\
\hline Wrist & +1 & & & & \\
\hline Wrist twist & +1 & & & & \\
\hline Muscle Use & & & +1 & - & - \\
\hline Force/Load & & & +0 & - & - \\
\hline \multicolumn{2}{|c|}{ Final Wrist, Arm, Score } & (Total Score 1) & & +2 & \\
\hline Neck & +1 & \multirow{3}{*}{ Posture Score B } & \multirow{3}{*}{+1} & \multirow{3}{*}{-} & \multirow{3}{*}{-} \\
\hline Trunk & +1 & & & & \\
\hline Leg & +1 & & & & \\
\hline Muscle Use & & & +1 & - & - \\
\hline Force/Load & & & +0 & - & - \\
\hline \multicolumn{4}{|c|}{ Final Neck, Trunk \& Leg Score (Total Score 2) } & +2 & - \\
\hline \multicolumn{4}{|c|}{ FINAL SCORE } & & +2 \\
\hline
\end{tabular}




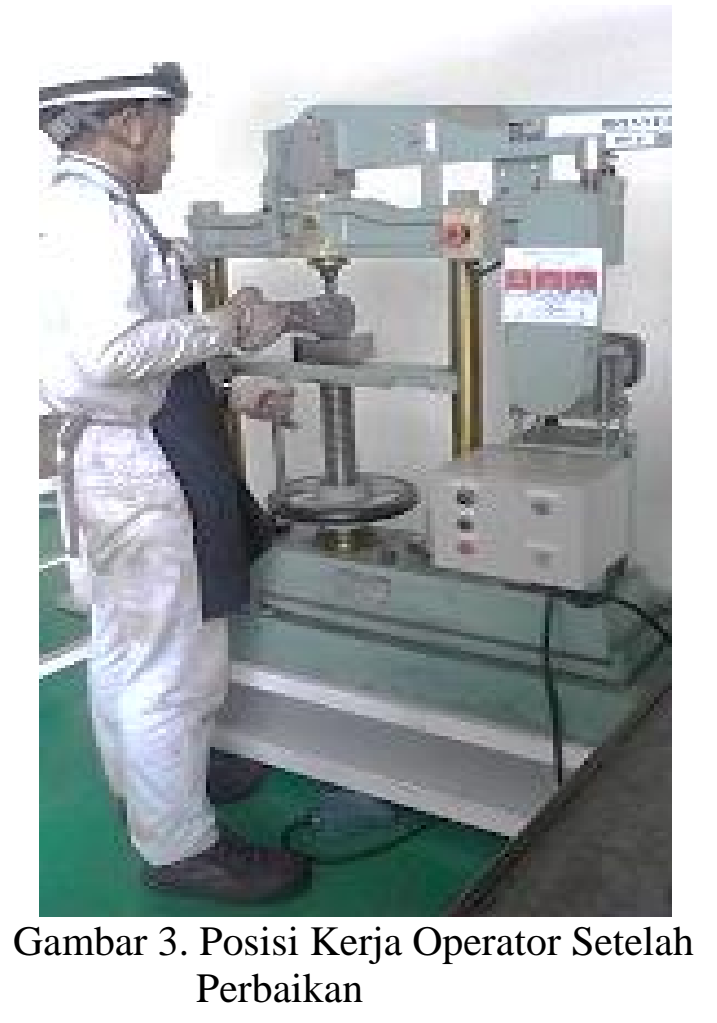

KESIMPULAN

Postur kerja operator yang membungkuk berdampak memberikan beban berlebih pada bagian leher dan punggung sehingga operator mudah mengalami kelelahan pada bagian tersebut. Hal ni dibuktikan dengan skor RULA yang tinggi yaitu 5 dan masuk dalam kategori perlu investigasi lebih lanjut dan segera dilakukan perubahan. Perbaikan yang dilakukan adalah meninggikan stasiun kerja agar operator tidak lagi membungkuk. Hal ini berhasil dibuktikan dengan menurunkan skor RULA dari 5 menjadi 2 dan masuk kategori acceptable (dapat diterima). Untuk saran penelitian kedepannya, akan lebih baik jika ketinggian meja kerja dapat disesuaikan dengan tinggi operator agar dapat lebih fleksibel untuk digunakan oleh operator lain dengan ketinggian berbeda. Atau dapat juga dengan menggunakan data anthopometri tinggi badan operator dalam menentukan tinggi support.

\section{DAFTAR PUSTAKA}

[1]. Wignjosoebroto, Sritomo, 2003, Ergonomi studi gerak dan waktu. Guna Widya. Surabaya

[2]. Susihono, W., 2009, Rancangan Ulang Mesin Pemotong Singkong Semi Otomatis dengan Memperhatikan Aspek-Aspek Ergonomis Kerja. Proceeding Seminar Nasional Aplikasi Program K3 dan Ergonomi ditempat Kerja. Univ. Sumatra Utara. Hal A12-1 s/dA12-10. Medan

[3]. Nurmianto, E., 1998, Ergonomi Konsep Dasar dan Aplikasinya, Edisi Kedua, Guna Widaya Insitut Teknologi Sepuluh Nopember, Surabaya.

[4]. Susihono, W., 2011, Analisis Postur Kerjadan Re-Desain Interior Kabin Masinis Lokomotif CC300. Seminar Nasional Teknik Industri. Universitas Gajah Mada Yogyakarta

[5]. Mc Atamney L \& Corlett N., 1993, Rapid Upper Limb Assessment (RULA): a survey method for the investigation of work-related upper limb disorders".

[6]. Lueder, 1996, University's Nottingham Institute of Occupational Ergonomics 